\title{
Harvard faces questions on missing data
}

[SAN DIEGO] The US Department of Veterans' Affairs is conducting an inquiry into whether the absence of documentation on key experiments leading to the publication of research carried out at a centre affiliated to Harvard Medical School should be treated as scientific misconduct.

Although internal investigations at Harvard last year led university officials to the conclusion that "it was not possible to ascertain whether the experiments had been done as described in the paper," they also decided that absence of documentation did not constitute scientific misconduct.

Officials of the veterans' affairs department, which funded the research, are now conducting their own investigation and reviewing the Harvard inquiry. Meanwhile, another federal agency is investigating a claim by a researcher that she lost her job after she questioned the paper when it was being submitted for publication.

The research concerns a genetic defect causing a Factor VII deficiency in an Italian patient. It was carried out under the direction of Kenneth A. Bauer, chief of haematology-oncology at the Veterans' Affairs Medical Center at West Roxbury, Massachusetts. The disputed experiments were carried out by Arnaldo A. Arbini, a physician from the
University of Milan who was doing research in Bauer's laboratory, and published last June in the journal Blood. Arbini has since moved to Yale University.

Bauer and Arbini say they received written reprimands from Harvard faculty authorities for the shortcomings in their data. Arbini admits that there was no laboratory notebook entry to document the questioned experiments, but says that this was because they were repetitions of earlier work. "In retrospect it obviously was a mistake," says Arbini. "But this was a completely innocent omission."

Bauer denies that there was any attempt to falsify data or any "wilful misrepresentation of data". He calls the missing data "an inexplicable lapse".

In a letter last October to the researcher who questioned the paper, Margaret L. Dale, an attorney in Harvard's Office of Research Issues, admitted that "there was concern that a paper had been published reporting on experiments for which there were not extant primary data". But Dale wrote that there was not sufficient evidence to conclude that there was scientific misconduct.

Dale pointed out that the experiments "wẹre repeated in September under the supervision of an independent observer. As a

\section{Reform follows discontent at Tata institute}

[NEW DELHI] A major shake-up has been approved of the Tata Institute of

Fundamental Research in Mumbai (formerly Bombay), India's leading institute for basic studies in science and mathematics and the springboard for launching the country's nuclear programme in the 1940 s.

This follows recommendations of a committee of international scientists headed by the British Nobel prizewinner Lord Porter, professor of chemistry at Imperial College, London, and a former president of the Royal Society. Unofficially, the reforms are also said to have been prompted by discontent among research staff about the way the institute has been run in recent years.

The panel's remit was to review the working of the institute during the past 25 years and to identify a possible strategy for the next ten years.

The institute, which is funded by the Department of Atomic Energy, was set up in 1946 by the late Indian nuclear physicist Homi Jehangir Bhabha. "We thought it was time to take stock of the accomplishments of the institute and plan its future activities," says Rajagopala Chidambaram, secretary of the department.

Although the authorities do not admit it, the review was also prompted by the simmering discontent among the institute's academic staff who six years ago formed the Scientific Forum for the Tata Institute. This body told the review panel that the "rapid decline in the management of science in the institute" was a cause for concern, and that some of the problems "are so serious that they have caused the institute to remain stagnant".

In a letter submitted to the panel, the scientific forum said: "The shortsighted and self-centred policies of the authorities have made the scientists unhappy; there are serious difficulties in attracting new talent".

According to Tata scientists, the problems faced by the institute include subcritical research, poor management of research infrastructure, inadequate allocation of funds, unsatisfactory salary structure and lack of transparency and objectivity in personnel policies.

But Mambilikalathil Govind Kumar Menon, a former director of Tata and a member of its management council, says the problems are being exaggerated, adding that the review is long overdue.

The review panel's draft recommendations call for large-scale changes in the management, starting with the appointment of a new director from June. Chidambaram confirms that a search for a new director is taking place.

K.S. Jayaraman result of that process, it was determined that the paper could stand uncorrected." Peter V. Tishler, a Harvard physician who is associate chief of staff for education at the veterans' affairs department in West Roxbury, said he observed the repeating of the experiments.

The issue of whether the absence of primary data notebooks constitutes scientific misconduct has varied over the years. In a case in the late 1980s involving a former biochemist from Baylor College of Medicine in Houston, Texas, who made use of research results from a paper he was reviewing, the National Institutes of Health (NIH) decided that the absence of primary data was an important factor in finding misconduct.

But Christopher B. Pascal, acting director of the NIH's Office of Research Integrity (ORI), says that recent decisions show "the mere absence of records alone isn't sufficient proof of scientific misconduct". Pascal says that NIH is concerned that an individual might use a lack of records as an excuse for "dumping records" to cover up the fabrication of data. "The problem is, you have to prove intent," he says.

Paul M. Hoffman, the veterans' affairs department's director of medical research, says he is unable yet to make a judgement on whether the absence of primary data was scientific misconduct in the Harvard case. "It makes good sense that you should be able to document what you are publishing," says Hoffman, a neurovirology researcher. "If you can't, you can publish anything."

The same point is made by Dinah K. Bodkin, the former researcher in Bauer's laboratory who expressed concern about the Arbini paper. "Harvard has stood the definition of scientific misconduct on its head," she says.

Danielle Brian - executive director of the Project on Government Oversight in Washington, DC, which is assisting Bodkin - calls Harvard's conclusion about the lack of notebooks "patently absurd". In seeking a thorough investigation by the veterans' affairs department, Brian wrote that Harvard's handling of the case "appears to fly in the face of overwhelming facts". Don Gibbons, a spokesman for Harvard, says that the university thoroughly investigated the complaint before issuing its opinion last October.

Bodkin, who was not a co-author of the disputed paper, filed a claim of retaliation last year against Bauer for dropping her from his laboratory team immediately after she questioned Arbini's research in December 1995. Bauer denied the charge, saying that Bodkin's funding was running out and there were problems with her productivity. The US Office of Special Counsel, a watchdog agency that investigates such claims of retaliation against federal employees, is carrying out its own investigation.

RexDalton 